\title{
Influence of chemical treatment on the tensile properties of kenaf fiber reinforced thermoplastic polyurethane composite
}

\author{
Y. A. El-Shekeil ${ }^{*}$, S. M. Sapuan ${ }^{1}$, A. Khalina ${ }^{2}$, E. S. Zainudin ${ }^{3}$, O. M. Al-Shuja'a ${ }^{4}$ \\ ${ }^{1}$ Department of Mechanical and Manufacturing Engineering, Universiti Putra Malaysia, 43400 Serdang, Selangor, \\ Malaysia \\ ${ }^{2}$ Department of Biological and Agricultural Engineering, Universiti Putra Malaysia, 43400 Serdang, Selangor, Malaysia \\ ${ }^{3}$ Laboratory of Bio-Composite Technology, Institute of Tropical Forestry and Forest Products, Universiti Putra Malaysia, \\ 43400 Serdang, Selangor, Malaysia \\ ${ }^{4}$ Department of Chemistry, Faculty of Applied Science, Thamar University, Thamar, Yemen
}

Received 15 June 2012; accepted in revised form 1 August 2012

\begin{abstract}
In this study, the effect of polymeric Methylene Diphenyl Diisocyanate (pMDI) chemical treatment on kenaf (Hibiscus cannabinus) reinforced thermoplastic polyurethane (TPU/KF) was examined using two different procedures. The first consisted of treating the fibers with $4 \%$ pMDI, and the second involved $2 \% \mathrm{NaOH}+4 \%$ pMDI. The composites were characterized according to their tensile properties, Fourier Transform Infrared Spectroscopy (FTIR) and Scanning Electron Microscopy (SEM). The treatment of the composite with 4\% pMDI did not significantly affect its tensile properties, but the treatment with $2 \% \mathrm{NaOH}+4 \%$ pMDI significantly increased the tensile properties of the composite (i.e., 30 and $42 \%$ increases in the tensile strength and modulus, respectively). FTIR also showed that treatment with $2 \% \mathrm{NaOH}+4 \% \mathrm{pMDI}$ led to the strongest H-bonding. Additionally, the surface morphology of specimens after tensile fracture confirmed that the composite treated with $2 \% \mathrm{NaOH}+4 \%$ pMDI had the best adhesion and wettability.
\end{abstract}

Keywords: polymer composites, thermoplastic polyurethane, kenaf fibers, pMDI chemical treatment, FTIR

\section{Introduction}

Natural fiber composites are having a strong influence in the field of composite materials. Cost effectiveness, a lighter weight, lower abrasion of equipment and renewability are amongst the benefits of natural fiber composites. However, natural fiber composites face some difficulties that prevent their widespread use. Fiber-polymer incompatibility has been the subject of previous studies [1-4]. This incompatibility is caused by the hydrophilic nature of the fibers and the hydrophobic nature of many polymers used in this field. The presence of hemi- cellulose, lignin and other impurities also causes a lack of adhesion between fibers and polymers.

The kenaf plant has a single, straight, unbranched stem. It has a short growing period, high biomass output and good mechanical properties. It reaches 3-4 meters in height in 4-5 months. It is reported that kenaf can yield three times a year in Malaysian climates [5], and in terms of quantity it can yield 2 to 25 ton/acre, depending on many factors such as soil type, variety and the month of planting [6]. Kenaf is traditionally used in cordage, canvas and sacking [7]. Kenaf is a good alternative to wood in the pulp and paper industry [3].

\footnotetext{
${ }^{*}$ Corresponding author, e-mail: y_shekeil@yahoo.com
}

(c) BME-PT 
Kenaf reinforced thermoplastic polyurethane was developed by the authors in a previous study [8]. Kenaf bast fiber was used because of its fast growth and good mechanical properties. Kenaf also absorbs nitrogen and phosphorus from the soil and accumulates carbon dioxide at a considerably high rate [9]. Thermoplastic polyurethane (TPU) was chosen due to its good mechanical properties and rubber-like elasticity. Another reason for selecting TPU is that polyurethane is polar, which reduces the fiber-polymer incompatibility.

Previously, the effect of various treatments on TPU/ $\mathrm{KF}$ composites has been considered. The pretreatment of fibers with different concentrations of $\mathrm{NaOH}$ resulted in deterioration of its mechanical properties [10]. This result was supported by FTIR, thermogravimetrical analysis TGA and SEM studies.

Using pMDI isocyanate as an additive also showed no significant effect on the properties of the composite when $\mathrm{pMDI}$ was placed into the mixer directly before adding the fibers [11]. The NCO active group of isocyanate might have reacted with the matrix before the fibers were added to the mixer, which most likely resulted in the negligible effect on the properties of the composite.

Alkali treatment of natural fibers has several advantages for the removal of undesired substances; it affects the properties of the fibers and fiber-matrix interlocking [12]. Isocyanate has also shown a positive effect when used as a coupling agent between natural fibers and polymers. Previous studies have used isocyanates as coupling agents and reported their positive effect on fiber-matrix interfacial bonding [13-16]. Therefore, in this study, the same treatments (i.e., alkalization and isocyanate) were used with some modifications. Instead of charging the isocyanate into the mixer directly, it was used to pretreat the natural fibers, and in this case, it is referred to as pMDI chemical treatment. Alternatively, the fibers were first mercerized with $\mathrm{NaOH}$ and then treated with pMDI. Details on the chemical treatments are given in the methodology. The aim of this research is to investigate the effect of pMDI chemical treatment on TPU/KF composites.

\section{Experimental}

\subsection{Materials}

TPU (Texin ${ }^{\circledR}$ ) and pMDI (Desmodur ${ }^{\circledR} 44 \mathrm{~V} 10 \mathrm{~L}$ ) were obtained from Bayer Co. (Malaysia) Sdn Bhd,
Table 1. Characteristics of TPU

\begin{tabular}{|l|c|}
\hline Specific gravity & 1.21 \\
\hline Tensile strength & $48 \mathrm{MPa}$ \\
\hline Melting temperature & $210^{\circ} \mathrm{C}$ \\
\hline Hardness & $55 \mathrm{D}$ \\
\hline
\end{tabular}

Petaling Jaya, Selangor, Malaysia. The TPU used in this study was polyester based, and the properties are shown in (Table 1). pMDI isocyanate has an NCO content of 30.5 to $32.5 \mathrm{wt} \%$. The kenaf V36 bast fiber used in this study was supplied by KEFI (Malaysia) Sdn Bhd, Setiu, Terengganu, Malaysia.

\subsection{Fiber preparation}

Mechanical decortication was used to extract the bast fibers. The fibers were pulverized using a Fritsch Power Cutting Mill PULVERISETTE 25 (Fritsch $\mathrm{GmbH}$, Laborgeraetebau, Germany). The fibers were subsequently sieved using an automatic shaker sieve with meshes of 50 to 120 to a size range of $125-300 \mu \mathrm{m}$. This fiber size exhibited the optimum mechanical properties for TPU/KF composites [8].

\subsection{Fiber treatments}

\subsubsection{Alkali treatment}

The fibers were treated using a $2 \%$ aqueous solution of $\mathrm{NaOH}$ (by weight). The fibers were soaked in the solution for 3 hours. Subsequently, the fibers were washed 6 times with distilled water and oven dried at $80^{\circ} \mathrm{C}$ for 24 hours.

\subsection{2. pMDI chemical treatment}

Kenaf was pre-treated with $4 \%$ pMDI by weight of the fiber as follows. First, kenaf was mixed with toluene in a flask. Then, pMDI was mixed with toluene in a dropping funnel and then dropped into the flask over 20 minutes. The flask was heated at $50^{\circ} \mathrm{C}$ on a flat heater with continuous mixing for one hour. After the treatment, the treated fibers were separated by filtration, washed several times with toluene and dried in an oven at $70^{\circ} \mathrm{C}$ for 2 hours.

\subsection{Composite preparation}

\subsubsection{Internal mixer}

The TPU/KF composite was mixed using a Haake Polydrive R600 internal mixer at $190^{\circ} \mathrm{C}$ for $11 \mathrm{~min}$ utes at $40 \mathrm{rpm}$. These parameters were used because they led to the optimum tensile strength of the TPU/ KF composite [8]. A 30\% fiber loading was used 
Table 2. The four different formulations prepared in this study

\begin{tabular}{|c|c|c|}
\hline \multirow{2}{*}{ Formulation } & \multicolumn{2}{|c|}{ Treatment } \\
\cline { 2 - 3 } & NaOH [\%] & pMDI [\%] \\
\hline COMP1 & - & - \\
\hline COMP2 & 2 & - \\
\hline COMP3 & - & 4 \\
\hline COMP4 & 2 & 4 \\
\hline
\end{tabular}

throughout the study because it resulted in the optimal strength of the composite [17]. TPU was charged into the mixer until the torque was stabilized, and then the fiber was added into the mixer. This procedure is explained in detail in a previous study [8]. Four different formulations were prepared in this study, as shown in (Table 2).

\subsubsection{Compression molding}

The sample was pre-heated for 7 minutes at $190^{\circ} \mathrm{C}$. Then sample was hot-pressed using a Vechno Vation 40 ton compression molding device for 10 minutes at $190^{\circ} \mathrm{C}$. Afterwards, the sample was cold pressed at $25^{\circ} \mathrm{C}$ for 5 minutes.

\subsection{Tensile testing}

The tensile properties were measured using an Instron 3365 electronic universal testing machine (Instron Co., Norwood, MA, USA) according to ASTM D 638(2010). The specimens were prepared by cutting them into dumbbell shapes using a hydraulic cutter machine. Five specimens were tested with a crosshead speed of $5 \mathrm{~mm} / \mathrm{min}$.

\subsection{FTIR spectra characterization}

The FTIR spectra of raw fibers, treated fibers and composites with and without treatment were recorded in the range of 4000 to $400 \mathrm{~cm}^{-1}$ using an FTIR machine Model Perkin-Elmer Spectrum 100 FT-IR Spectrometer (Perkin-Elmer, Norwalk, CT, USA). The samples were compacted into thin pellets with potassium bromide.

\subsection{Surface characterization}

The morphology of the tensile fracture surfaces of the treated and untreated composites were investigated using a scanning electron microscopy (SEM) on (S-3400 SEM, Hitachi Ltd., Ibaraki, Japan). The voltage used in the test was $5 \mathrm{kV}$.

\section{Results and discussion}

\subsection{Effect of chemical treatment on the tensile properties of TPU/KF}

Figure 1 shows the effect of various treatments on the tensile properties of TPU/KF. NaOH treatment of COMP2 decreased the tensile strength and strain; however, it slightly increased the tensile modulus. The pMDI chemical treatment of COMP3 resulted in a slight increase in the tensile strength and modulus and a slight decrease in the strain. The tensile strength of COMP4 showed a significant increase from $33 \mathrm{MPa}$ for the untreated composite (COMP1)
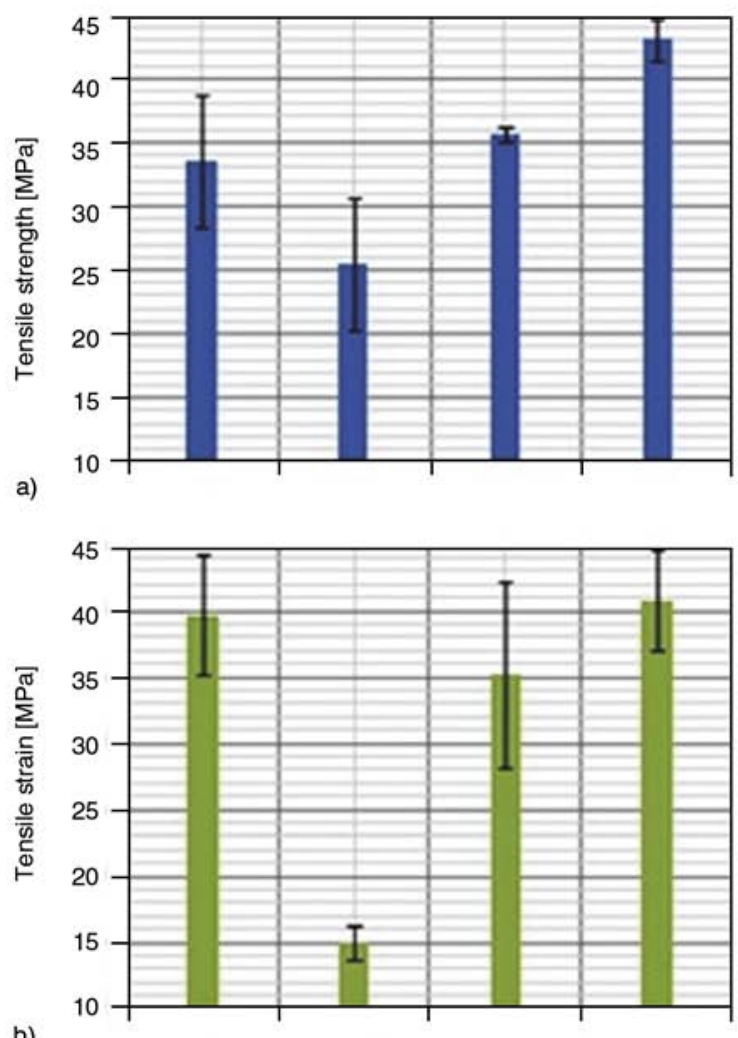

b)

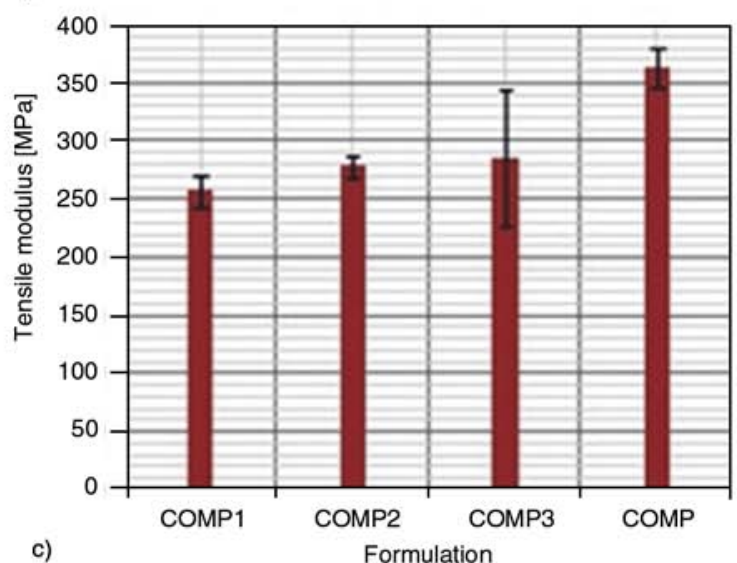

Figure 1. Effect of various treatments on the tensile properties of TPU/KF. (a) tensile strength, (b) tensile strain, (c) tensile modulus. 
to a mean value of $43 \mathrm{MPa}$ after treatment, which is an increase of approximately $30 \%$. The modulus also increased from $257 \mathrm{MPa}$ for the untreated composite to $364 \mathrm{MPa}$ after treatment, about a $42 \%$ increase, while strain to failure increased only slightly.

In COMP1, the fibers were untreated, and the fiber bundles were still strongly bonded to each other with high stacking. Mixing the fibers with TPU led to interfacial bonding with the surface without reaching the inside of the structure of the fiber bundles. The strength of the COMP1 was most likely a result of the natural cohesion of the untreated fiber bundles.

In COMP2, the fibers were treated with $\mathrm{NaOH}$, which cleaned them and provided a rougher surface; however, it softened the inter-febrillar matrix, which negatively affected the stress transfer in the fibers [12]. Alkali treatment uncovers the fibrils and gives the fibers a rough surface topography [18]. Alkali treatment also changes the fine structure of the native cellulose I to cellulose II by a process known as alkalization [18-20]. The reaction of $\mathrm{NaOH}$ with cellulose is shown in Equation (1). Figure 2a shows the surface of an untreated fiber. The fiber surface is smooth as a result of oils and waxes. Figure $2 b$ shows kenaf fibers treated with $2 \% \mathrm{NaOH}$. It is clear that the treatment removes a certain amount of hemicellulose, lignin, wax, oils, and other impurities, and the surface becomes rougher. Similar observations were found in a previous study [21]. It has been demonstrated that TPU is not compatible with $\mathrm{NaOH}$ treatment [10]. $\mathrm{NaOH}$ treatment was used in this study to compare COMP2 with COMP4, which was treated with pMDI at the same alkali dosage (Equation (1)):

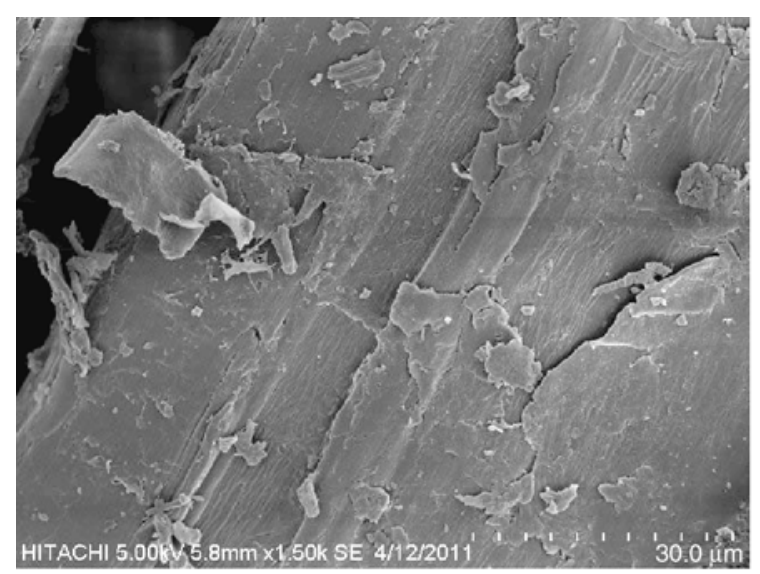

a)
Fiber $-\mathrm{OH}+\mathrm{NaOH} \rightarrow$

Fiber $-\mathrm{O}^{-} \mathrm{Na}^{+}{ }_{-} \mathrm{H}_{2} \mathrm{O}+$ (Surface impurities)

In COMP3, the fibers were treated with pMDI. The $\mathrm{NCO}$ groups are believed to react with the $\mathrm{OH}$ groups of the cellulose; therefore, the composite exhibited better interfacial bonding between the treated fibers and the matrix. However, the increment of the tensile strength was not significant, which is attributed to the availability of other materials, such as hemicellulose, lignin, waxes, and oils, which may have prevented the full effect of the isocyanate treatment. Therefore, in the next formulation, the fibers were first treated with $\mathrm{NaOH}$ to remove the undesirable impurities that reduce the ability of pMDI to form effective crosslinks during the treatment of fibers.

In COMP4, the fibers were treated with $\mathrm{NaOH}$, which removed undesirable materials; thus, more reactive sites (i.e., hydroxyl groups) of cellulose were revealed [12]. Then, the fibers were treated with pMDI. In general, polyurethane consists of two main components: isocyanates and polyols. The main reaction that forms polyurethane is the reaction between the isocyanate $\mathrm{NCO}$ groups and the $\mathrm{OH}$ groups of the polyols. Isocyanate represents the rigid segment while polyol represents the soft component [22]. It is believed that isocyanate played the same role when utilized as a chemical treatment for the $\mathrm{NaOH}$ pretreated kenaf fibers; thus, by adding isocyanate to the fibers, they became more rigid. More rigid fibers have a better ability to transfer the load to the matrix. In other words, the NCO groups could react more effectively with the $\mathrm{OH}$ groups after $\mathrm{NaOH}$ treatment because the fibers had more

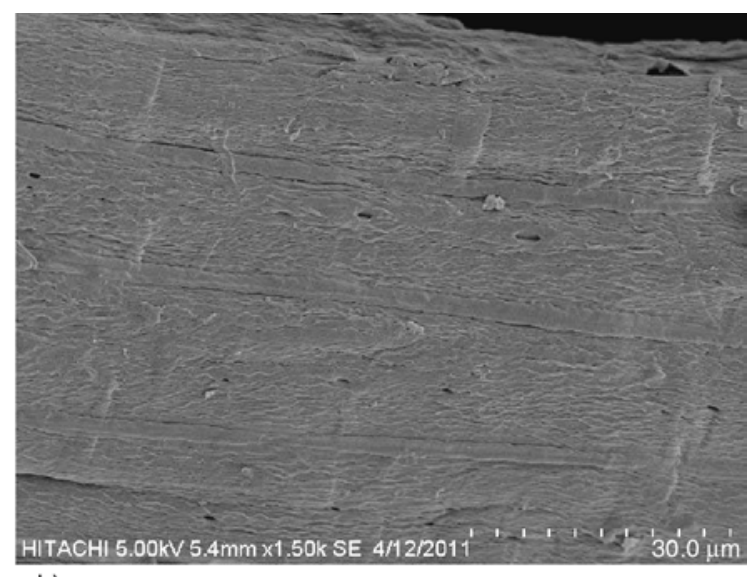

b)

Figure 2. SEM of (a) untreated kenaf fiber and (b) kenaf fiber treated with $2 \% \mathrm{NaOH}$ [10] 


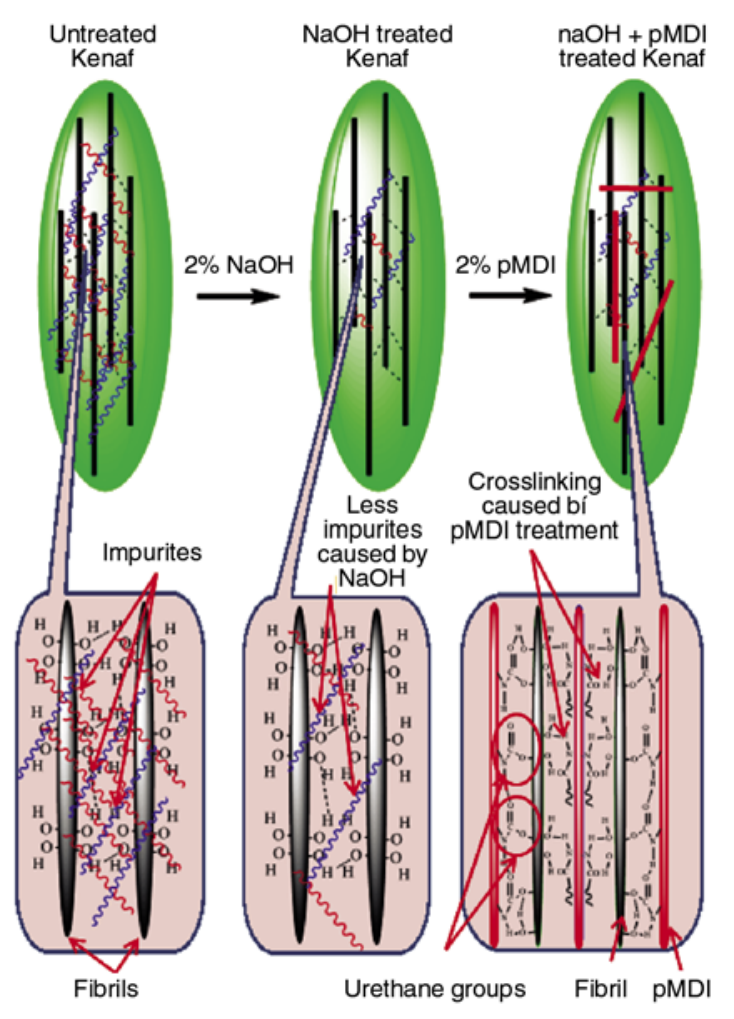

Figure 3. Schematic hypothetical chemical structure of kenaf fibers treated with $2 \% \mathrm{NaOH}+4 \%$ pMDI

available reactive sites for the NCO groups. The crosslinking reconstructed the fibers and made them stronger; thus, they were able to transfer more load. In addition, the increase of strength in COMP4 could be ascribed to the increased strength of the interface between the fibers and the matrix, thereby allowing the fibers to positively contribute.

A schematic hypothetical chemical structure of the fibers treated with $2 \% \mathrm{NaOH}+4 \%$ pMDI is shown in Figure 3. In this drawing, untreated kenaf is covered with undesirable materials. However, after treatment with $\mathrm{NaOH}$, the fibers were coated with fewer impurities. After treatment with pMDI, crosslinking can be observed between the $\mathrm{OH}$ groups of the fibrils and pMDI to form urethane groups.

\subsection{FTIR spectra of treated and untreated fibers and composites}

Figure 4 shows the FTIR spectra of curve (a) untreated kenaf fibers, curve (b) kenaf fibers treated with $2 \% \mathrm{NaOH}$, curve (c) kenaf fibers treated with 4\% pMDI, curve (d) kenaf fibers treated with $2 \% \mathrm{NaOH}+4 \%$ pMDI, and curve (e) pMDI. Figure 5 shows the FTIR spectra of COMP1, COMP2, COMP3, COMP4, and pure TPU. The main IR bands

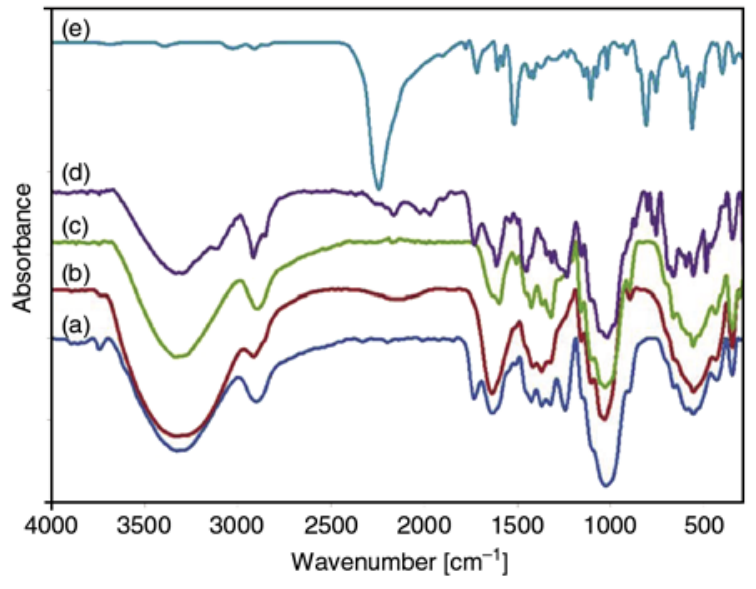

Figure 4. FTIR spectra of (a) untreated kenaf fibers, (b) kenaf fibers treated with $2 \% \mathrm{NaOH}$, (c) kenaf fibers treated with $4 \%$ pMDI, (d) kenaf fibers treated with $2 \% \mathrm{NaOH}+4 \%$ pMDI and (e) pMDI

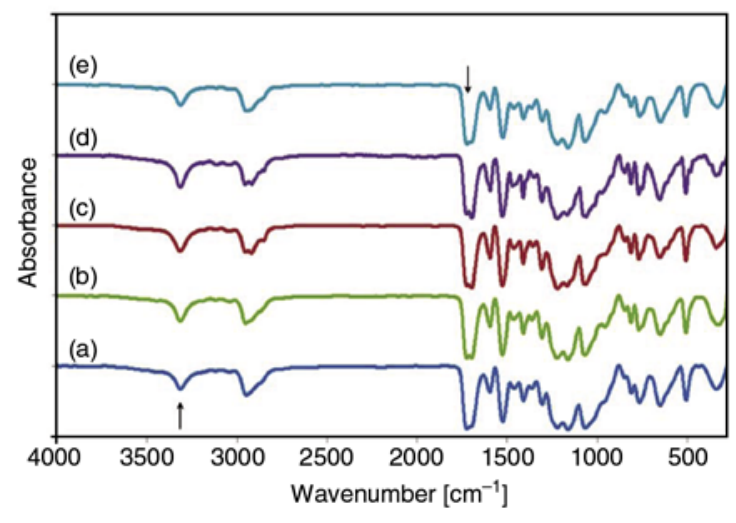

Figure 5. FTIR spectra of (a) COMP1, (b) COMP2, (c) COMP3, (d) COMP4 and (e) TPU

for all of the previous materials are summarized in (Table 3).

In the untreated kenaf spectra, the absorption peak was observed at approximately $1736 \mathrm{~cm}^{-1}$, corresponding to the $\mathrm{C}=\mathrm{O}$ stretching of hemicellulose, but this peak was almost missing in the spectrum of the $2 \% \mathrm{NaOH}$ treated fibers, indicating the elimination of hemicelluloses and lignin as a result of alkali treatment. The elimination of this peak was observed in a previous study [23]. It is observed again at $1730 \mathrm{~cm}^{-1}$ in some materials after alkali treatment such as kenaf treated with $2 \% \mathrm{NaOH}+4 \%$ pMDI, $\mathrm{TPU} / \mathrm{KF}, \mathrm{TPU} / \mathrm{KF}$ treated with $2 \% \mathrm{NaOH}, \mathrm{TPU} / \mathrm{KF}$ treated with $4 \% \mathrm{pMDI}$, and TPU/KF treated with $2 \% \mathrm{NaOH}+4 \%$ pMDI as a result of the formation of $v(\mathrm{C}=\mathrm{O})$ of free urethane.

The strong absorption at $2250 \mathrm{~cm}^{-1}$ corresponds to the $-\mathrm{N}=\mathrm{C}=\mathrm{O}$ stretching of pMDI. This peak was 
Table 3. Main FTIR bands of kenaf, pMDI, TPU, kenaf treated with $2 \% \mathrm{NaOH}$, kenaf treated with $4 \%$ pMDI, kenaf treated with $4 \%$ pMDI, kenaf treated with $2 \% \mathrm{NaOH}+4 \%$ pMDI, COMP1, COMP2, COMP3, and COMP4

\begin{tabular}{|c|c|c|c|c|c|c|c|c|c|c|c|}
\hline \multicolumn{2}{|c|}{ Main peaks } & \multirow{2}{*}{ Kenaf } & \multirow{2}{*}{ pMDI } & \multirow{2}{*}{ TPU } & \multirow{2}{*}{$\begin{array}{c}\text { Kenaf }+ \\
\mathrm{NaOH}\end{array}$} & \multirow{2}{*}{$\begin{array}{c}\text { Kenaf }+ \\
\text { pMDI }\end{array}$} & \multirow{2}{*}{$\begin{array}{c}\text { Kenaf }+ \\
\mathrm{NaOH}+ \\
\text { pMDI }\end{array}$} & \multirow{2}{*}{ COMP1 } & \multirow{2}{*}{ COMP2 } & \multirow{2}{*}{ COMP3 } & \multirow{2}{*}{ COMP4 } \\
\hline $\begin{array}{l}\text { Chemical } \\
\text { structure }\end{array}$ & $\mathbf{P L}$ & & & & & & & & & & \\
\hline $\mathrm{NH}^{\mathrm{a}}$ & $3420-3200$ & - & - & 3324 & - & 3351 & 3346 & 3325 & 3322 & 3325 & 3324 \\
\hline $\mathrm{OH}^{\mathrm{a}}$ & $3300-3400$ & 3340 & - & - & 3347 & 3313 & 3300 & - & - & - & - \\
\hline $\mathrm{C}-\mathrm{H}^{\mathrm{a}}$ & $3100-3000$ & - & 3040 & - & - & - & - & - & - & 3060 & - \\
\hline $\begin{array}{l}\mathrm{CH}_{2}{ }^{\mathrm{a}} \text { and } \\
\mathrm{CH}_{3}{ }^{\mathrm{a}}\end{array}$ & $3000-2800$ & 2924 & 2927 & $\begin{array}{l}2985, \\
2936\end{array}$ & 2931 & 2910 & 2910 & 2958 & $\begin{array}{l}2961, \\
2935\end{array}$ & $\begin{array}{l}2961, \\
2927\end{array}$ & $\begin{array}{l}2961, \\
2925\end{array}$ \\
\hline$-\mathrm{N}=\mathrm{C}=\mathrm{O}^{\mathrm{b}}$ & 2250 & - & 2250 & - & - & - & - & - & - & - & - \\
\hline $\mathrm{NH}^{\mathrm{c}}$ & $1590-1650$ & - & 1603 & - & 1602 & 1603 & 1603 & 1603 & 1601 & 1600 & 1598 \\
\hline $\mathrm{C}=\mathrm{O}^{\mathrm{d}}$ & 1690 & 1736 & - & 1729 & - & - & - & 1728 & 1729 & 1729 & 1730 \\
\hline $\mathrm{C}=\mathrm{O}^{\mathrm{e}}$ & 1740 & - & - & 1715 & - & - & - & 1713 & 1703 & 1705 & 1702 \\
\hline $\mathrm{C}=\mathrm{C}^{\mathrm{a}}$ & 1600 & 1647 & $\begin{array}{l}1610 \\
1521\end{array}$ & - & - & 1641 & - & - & - & - & - \\
\hline $\begin{array}{l}\mathrm{H}-\mathrm{N}-\mathrm{C}=\mathrm{O} \\
\text { Amide } \mathrm{II}^{\mathrm{f}}\end{array}$ & $1550-1510$ & - & - & 1530 & - & - & - & 1531 & 1532 & 1531 & 1531 \\
\hline $\begin{array}{l}\mathrm{CH}_{2}{ }^{\mathrm{c}} \text { and } \\
\mathrm{CH}_{3}{ }^{\mathrm{c}}\end{array}$ & $1500-1300$ & - & - & - & - & $\begin{array}{l}1428 \\
1323\end{array}$ & $\begin{array}{l}1426, \\
1321\end{array}$ & - & - & 1415 & $\begin{array}{l}1414, \\
1312\end{array}$ \\
\hline $\mathrm{C}-\mathrm{O}^{\mathrm{a}}$ & $1300-1000$ & 1042 & - & - & 1044 & 1040 & 1038 & 1075 & 1078 & 1076 & 1076 \\
\hline
\end{tabular}

P L; peak location $\left[\mathrm{cm}^{-1}\right]$, ${ }^{\mathrm{a}}$ stretching, ${ }^{\mathrm{b}}$ isocyanate, ${ }^{\mathrm{c}}$ bending, ${ }^{\mathrm{d}}$ non-bonded urethane stretching, ${ }^{\mathrm{e}}$ associated urethane, ${ }^{\mathrm{f}}$ combined motion

almost missing in the spectrum of the pMDI treated fibers (Figure 4) and composites (Figure 5), which confirms that presence of the urethane group formed between kenaf and pMDI in pMDI chemically treated fibers and between pMDI chemically treated fibers and TPU in TPU/KF. The elimination of the peak at $2250 \mathrm{~cm}^{-1}$ indicating $-\mathrm{N}=\mathrm{C}=\mathrm{O}$ stretching of pMDI, with a corresponding increase in the peak at $1730 \mathrm{~cm}^{-1}$, mentioned in the previous paragraph, suggests the formation of carbamate esters as a result of the reaction between $-\mathrm{N}=\mathrm{C}=\mathrm{O}$ and $\mathrm{OH}$ [24].

The following observations were made for untreated kenaf, kenaf treated with $2 \% \mathrm{NaOH}$, kenaf treated with $4 \%$ pMDI, and kenaf treated with $2 \% \mathrm{NaOH}+$ $4 \%$ pMDI. Untreated kenaf and kenaf treated with $2 \% \mathrm{NaOH}$ have alcoholic $\mathrm{O}-\mathrm{H}$ stretching absorptions at approximately $3340 \mathrm{~cm}^{-1}$. However, kenaf treated with $4 \%$ pMDI and kenaf treated with $2 \% \mathrm{NaOH}+4 \%$ pMDI have overlapping signals of alcoholic $\mathrm{O}-\mathrm{H}$ stretching with $\mathrm{H}-$-bonded absorption and $\mathrm{N}-\mathrm{H}$ stretching with $\mathrm{H}$-bonded absorption at approximately $3340 \mathrm{~cm}^{-1}$.

TPU, TPU/KF, TPU/KF treated with $2 \% \mathrm{NaOH}$, TPU/KF treated with $4 \% \mathrm{pMDI}$, and TPU/KF treated with $2 \% \mathrm{NaOH}+4 \%$ pMDI were studied. All of these samples include urethane $\mathrm{N}-\mathrm{H}$ stretching and $\mathrm{N}-\mathrm{H}$ bending absorptions at approximately 3324 and $1530 \mathrm{~cm}^{-1}$, respectively, and $\mathrm{C}=\mathrm{O}$ stretching absorptions at approximately $1701 \mathrm{~cm}^{-1}$. The stretching absorption of an ether linkage $(\mathrm{C}-\mathrm{O}-\mathrm{C})$ was observed at approximately $1040 \mathrm{~cm}^{-1}$. In addition, absorption bands arising from $-\mathrm{CH}_{2}$ stretching were found between 2910 and $2985 \mathrm{~cm}^{-1}$, and bending $-\mathrm{CH}_{2}$ band were observed at approximately 1428 and $1323 \mathrm{~cm}^{-1}$.

The main factor contributing to the mechanical properties of the natural fiber composites is H-bonding. It causes shifts and differences in the intensities of the absorptions; all of these shifts are shown in Figure 6. For example, the stretching H-bonding of $\mathrm{NH}$ at approximately $3324 \mathrm{~cm}^{-1}$ [25] showed the highest absorption intensity from TPU/KF treated with $2 \% \mathrm{NaOH}+4 \%$ pMDI and the lowest absorp-

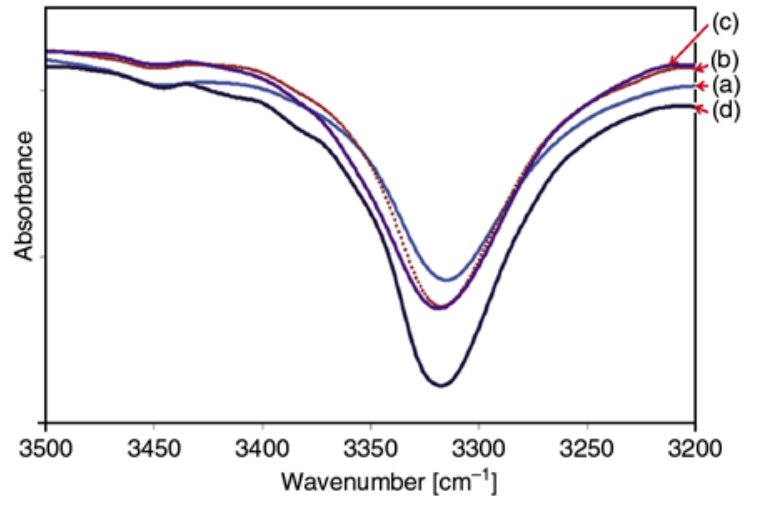

Figure 6. FTIR spectra in the range between 3500 and $3200 \mathrm{~cm}^{-1}$ for (a) COMP1, (b) COMP2, (c) COMP3 and (d) COMP4 
tion intensity from untreated TPU/KF, which indicates that the $\mathrm{H}$-bonding increased in the following order: TPU/KF treated with $2 \% \mathrm{NaOH}+4 \% \mathrm{pMDI}$, TPU/KF treated with $4 \% \mathrm{pMDI}$, TPU/KF treated $2 \% \mathrm{NaOH}$ and untreated TPU/KF.

$\mathrm{TPU} / \mathrm{KF}$ treated with $2 \% \mathrm{NaOH}+4 \%$ pMDI yielded the highest $\mathrm{H}$-bonding and thus, the best tensile properties because undesirable materials were removed from the kenaf by the $\mathrm{NaOH}$ treatment, and then the fibers were treated with pMDI to create chemical crosslinking between the fiber bundles. By following these steps, the degree of polymerization might have increased. In addition, urethane groups were formed, which made the fibers capable of transferring greater loads. Therefore, the tensile properties were enhanced.

\subsection{SEM of the fracture surface of tensile specimens}

Both fiber breakage and fiber pull-out are shown on the fracture surface of the untreated TPU/KF (Figure 7a), which indicates that the fiber-matrix adhesion is quite good. Figure $7 \mathrm{~b}$ shows the fracture surface of TPU/KF treated with $2 \% \mathrm{NaOH}$, in which

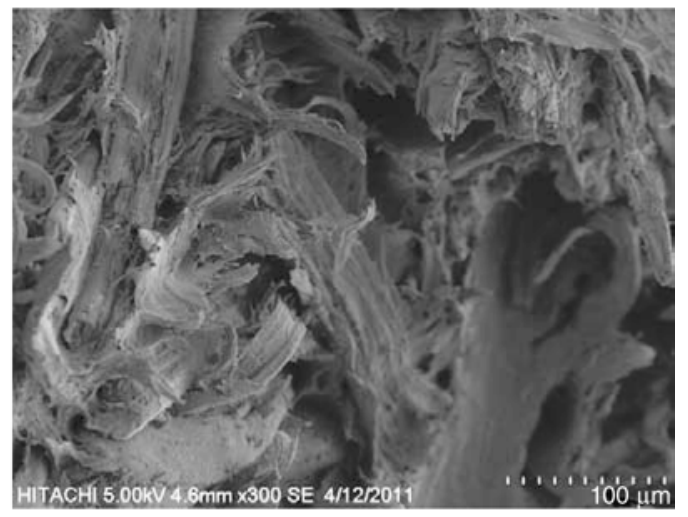

a)

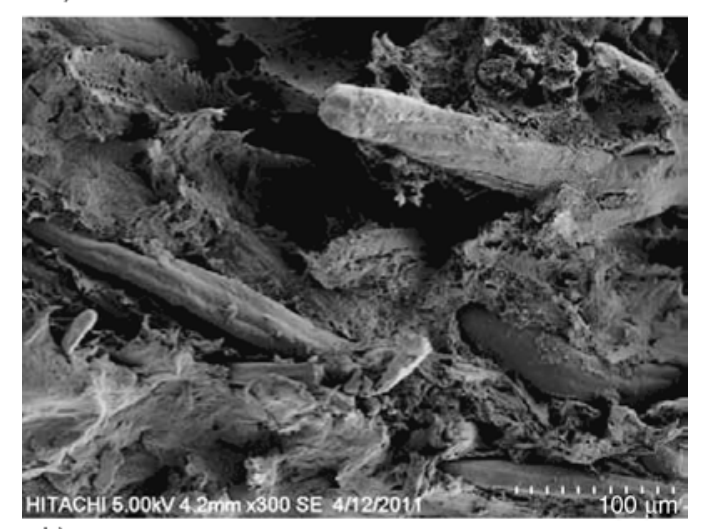

b)

Figure 7. SEM of (a) untreated TPU/KF and (b) TPU/KF treated with $2 \% \mathrm{NaOH}[10]$

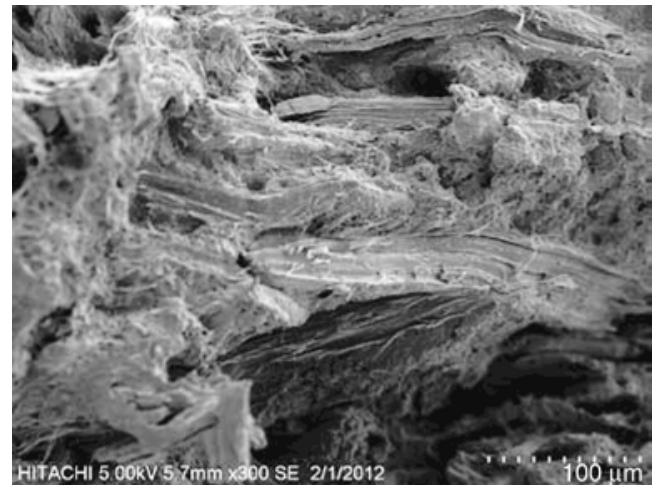

Figure 8. SEM of TPU/KF treated with $4 \%$ pMDI chemical treatment

poor fiber-matrix adhesion is confirmed by the presence of gaps between the fibers and the matrix and fiber pull-outs.

Treatment of TPU/KF with 4\% pMDI also led to a mix of fiber breakage and pull-outs Figure 8. However, when TPU/KF was treated with $2 \% \mathrm{NaOH}+$ $4 \%$ pMDI, fiber breakage became dominant, as shown in Figure 9a, which confirms the strong fibermatrix adhesion. Furthermore, no gaps were seen between the fibers and the matrix in Figure 9b, which is a high magnification image of Figure 9a,

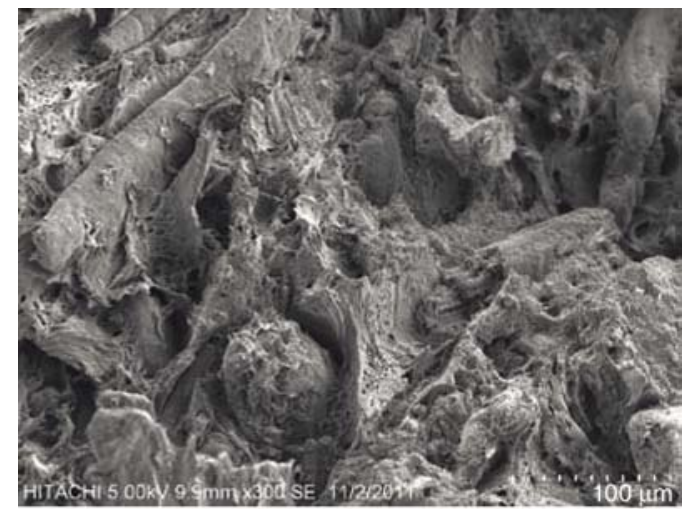

a)

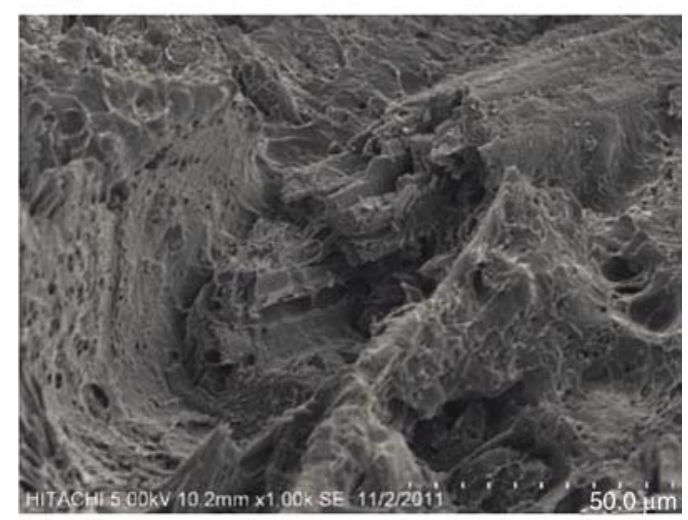

b)

Figure 9. SEM of TPU/KF treated with $2 \% \mathrm{NaOH}+$ $4 \%$ pMDI; (a) low magnification, (b) high magnification 
indicating better wetting and adhesion between the fibers and matrix.

\section{Conclusions}

While the treatment of composites with $\mathrm{NaOH}$ alone led to a deterioration of their properties, pMDI chemical treatment increased the properties of the composite only slightly. However, the treatment of kenaf fibers with $\mathrm{NaOH}$ followed by pMDI had a significant effect on the composite, which was evident in the $30 \%$ increase in the tensile strength and approximately $42 \%$ increase in the tensile modulus. The FTIR spectra also provided evidence that the NCO groups of pMDI covalently linked with the $\mathrm{OH}$ groups of kenaf fibers and that there was strong $\mathrm{H}$-bonding in the composite treated with $\mathrm{NaOH}+$ pMDI. The SEM morphological study shows that the composites treated with $\mathrm{NaOH}+$ pMDI have better fiber-matrix adhesion and wettability.

\section{Acknowledgements}

Parts of this paper have been published in a postgraduate seminar 'UPM-UniKL Symposium on Polymeric Materials', February 2012. The Fundamental Research Grant Scheme (FRGS), Ministry of Higher Education Malaysian grant number (01-10-10-924FR), is acknowledged for the support of this study. The authors would like to thank Bayer Co. (Malaysia) Sdn Bhd, Petaling Jaya, Selangor, Malaysia for the TPU supply and information provided.

\section{References}

[1] Bachtiar D., Sapuan S. M., Hamdan M. M.: The effect of alkaline treatment on tensile properties of sugar palm fibre reinforced epoxy composites. Materials and Design, 29, 1285-1290 (2008). DOI: $10.1016 /$ j.matdes.2007.09.006

[2] Bachtiar D., Salit M. S., Zainudin E., Abdan K., Mohd Dahlan K. Z. H.: Effects of alkaline treatment and a compatibilizing agent on tensile properties of sugar palm fibre-reinforced high impact polystyrene composites. BioResources, 6, 4815-4823 (2011).

[3] Viet Cao X., Ismail H., Rashid A. A., Takeichi T., VoHuu T.: Mechanical properties and water absorption of kenaf powder filled recycled high density polyethylene/natural rubber biocomposites using MAPE as a compatibilizer. BioResources, 6, 3260-3271 (2011).

[4] Wirawan R., Sapuan S. M., Yunus R., Abdan K.: Properties of sugarcane bagasse/poly(vinyl chloride) composites after various treatments. Journal of Composite Materials, 45, 1667-1674 (2011). DOI: $\underline{10.1177 / 0021998310385030}$
[5] Nosbi N., Akil H. M., Mohd Ishak Z. A., Abu Baker A.: Behavior of kenaf fibers after immersion in several water conditions. BioResources, 6, 950-960 (2011).

[6] Paridah M. T., Basher A. B., Syeed O. A., Ahmed Z.: Retting process of some bast plant fibres and its effect on fibre quality: A review. BioResources, 6, 52605281 (2011).

[7] Ibrahim M., Wan Daud W. R., Law K-N.: Comparative properties of soda pulps from stalk, bast, and core of Malaysian grown kenaf. BioResources, 6, 5074-5085 (2011).

[8] El-Shekeil Y. A., Salit M. S., Abdan K., Zainudin E. S.: Development of a new kenaf bast fiber-reinforced thermoplastic polyurethane composite. BioResources, 6, 4662-4672 (2011).

[9] Rashdi A. A. A., Sapuan S. M., Ahmad M., Abdan K. B.: Review of kenaf fiber reinforced polymer composites. Polimery, 54, 775-788 (2009).

[10] El-Shekeil Y. A., Sapuan S. M., Khalina A., Zainudin E. S., Al-Shuja'a O. M.: Effect of alkali treatment on mechanical and thermal properties of Kenaf fiber-reinforced thermoplastic polyurethane composite. Journal of Thermal Analysis and Calorimetry, 109, 1435-1443 (2012).

DOI: $10.1007 / \mathrm{s} 10973-012-2258-\mathrm{x}$

[11] El-Shekeil Y. A., Sapuan S. M., Khalina A., Zainudin E. S., Al-Shuja'a O. M.: Effect of isocyanate additive on mechanical and thermal properties of kenaf fiberreinforced thermoplastic polyurethane composite. Bulletin of Material Science, in press (2012).

[12] Thomas S., Pothan L.: Natural fibre reinforced polymer composites: From macro to nanoscale. Old City Publishing, Pothen (2009).

[13] Chen F., Liu L. S., Cooke P. H., Hicks K. B., Zhang J.: Performance enhancement of poly(lactic acid) and sugar beet pulp composites by improving interfacial adhesion and penetration. Industrial and Engineering Chemistry Research, 47, 8667-8675 (2008).

DOI: $10.1021 /$ ie $800930 j$

[14] Jiang L., Chen F., Qian J., Huang J., Wolcott M., Liu L., Zhang J.: Reinforcing and toughening effects of bamboo pulp fiber on poly(3-hydroxybutyrate-co-3hydroxyvalerate) fiber composites. Industrial and Engineering Chemistry Research, 49, 572-577 (2009). DOI: $10.1021 / \mathrm{ie} 900953 \mathrm{z}$

[15] Sahoo S., Misra M., Mohanty A. K.: Enhanced properties of lignin-based biodegradable polymer composites using injection moulding process. Composites Part A: Applied Science and Manufacturing, 42, 1710-1718 (2011).

DOI: 10.1016/j.compositesa.2011.07.025

[16] Wang Z., Wang E., Zhang S., Wang Z., Ren Y.: Effects of cross-linking on mechanical and physical properties of agricultural residues/recycled thermoplastics composites. Industrial Crops and Products, 29, 133-138 (2009).

DOI: $10.1016 /$ j.indcrop.2008.04.016 
[17] El-Shekeil Y. A., Sapuan S. M., Abdan K., Zainudin E. S.: Influence of fiber content on the mechanical and thermal properties of Kenaf fiber reinforced thermoplastic polyurethane composites. Materials and Design, 40, 299-303 (2012).

DOI: $\underline{10.1016 / \mathrm{j} . \text { matdes.2012.04.003 }}$

[18] Mwaikambo L. Y., Ansell M. P.: Chemical modification of hemp, sisal, jute, and kapok fibers by alkalization. Journal of Applied Polymer Science, 84, 22222234 (2002).

DOI: $10.1002 / a p p .10460$

[19] John M. J., Anandjiwala R. D.: Recent developments in chemical modification and characterization of natural fiber-reinforced composites. Polymer Composites, 29, 187-207 (2008). DOI: $10.1002 / p c .20461$

[20] Nevell T. P., Zeronian S. H.: Cellulose chemistry and its applications. Ellis Horwood, Chichester (1985).

[21] Liu X. Y., Dai G. C.: Surface modification and micromechanical properties of jute fiber mat reinforced polypropylene composites. Express Polymer Letters, 1, 299-307 (2007).

DOI: $\underline{10.3144 / \text { expresspolymlett.2007.43 }}$
[22] Thomson T: Polyurethanes as specialty chemicals: Principles and applications. CRC press, West Newbury (2004).

[23] Fávaro S. L., Ganzerli T. A., de Carvalho Neto A. G. V., da Silva O. R. R. F., Radovanovic E.: Chemical, morphological and mechanical analysis of sisal fiberreinforced recycled high-density polyethylene composites. Express Polymer Letters, 4, 465-473 (2010). DOI: 10.3144/expresspolymlett.2010.59

[24] Karmarkar A., Chauhan S. S., Modak J. M., Chanda M.: Mechanical properties of wood-fiber reinforced polypropylene composites: Effect of a novel compatibilizer with isocyanate functional group. Composites Part A: Applied Science and Manufacturing, 38, 227233 (2007).

DOI: 10.1016/j.compositesa.2006.05.005

[25] Silverstein R., Webster F.: Spectrometric identification of organic compounds. Wiley, New York (2006). 